\title{
Sulfate sulfur isotope evidence for enhanced pyrite burial in the aftermath of the Late Paleozoic great Ice Age
}

\author{
H. WU ${ }^{1 *}, \mathrm{Y} \mathrm{WANG}^{1}$, T. HE ${ }^{2}$, R. J. NEWTON ${ }^{2}$, B. CHEN $^{1}$, \\ Y.ZHANG ${ }^{3}$,T. YANG ${ }^{3}$.
}

${ }^{1}$ CAS Key Laboratory of Economic Stratigraphy and Palaeogeography, Nanjing Institute of Geology and Palaeontology Chinese Academy of Sciences, Nanjing 210008, China.(*hpwu@nigpas.ac.cn)

${ }^{2}$ School of Earth and Environment, University of Leeds, Leeds, LS2 9JT, UK.

${ }^{3}$ State Key Laboratory for Mineral Deposits Research, Department of Earth Sciences, Nanjing University, Nanjing 210093, China.

The early Permian witnessed the transition from the climax of the Late Paleozoic great Ice Age (LPIA) to the glacial meltdown period. The global climate during this interval developed from icehouse to greenhouse conditions, resulting in a great impact to marine chemistry, climatic characteristics and biodiversity evolution. As one of the most critical intervals during this transition, the Kungurian organicrich Chihsia formation of South China is commonly characterized as $\mathrm{O}_{2}$-deficient condition and incompatible high productivity. However, the relationship between increased biodiversity and marine redox condition is still unclear. Here we report carbonate-associated sulfate $S$-isotope data $\left(\delta^{34} S_{\mathrm{CAS}}\right)$ from three sections in the Yangtze platform in the aftermath of LPIA. We find relative stable trends in both $\delta^{34} \mathrm{~S}_{\mathrm{CAS}}$ (ranges between $15 \%$ to $25 \%$ ) and carbonate $\delta^{13} \mathrm{C}$ during Sakmarian and Artinskian stages. This is followed by an increasing $\delta^{34} \mathrm{~S}$ trend peaking at $+32 \%$ o during Kungurian, which can be explained by a gradual net increase in pyrite burial and expanded marine anoxia in the equatorial eastern Paleo-Tethys. Besides, global warming and ice sheet meltdown may have induced sea-level rise and shoaling of anoxic water during the Kungurian. Moreover, elevated continental weathering during this warm interval may have contributed to a larger flux of riverine sulfate and other nutrient input to the ocean and resulted in increased primary productivity and pyrite production. 